\title{
An EPIC model-based vulnerability assessment of wheat subject to drought
}

\author{
Yaojie Yue $\mathrm{Yu}^{1,2,7} \cdot$ Jian $\mathrm{Li}^{1} \cdot$ Xinyue $\mathrm{Ye}^{3} \cdot$ \\ Zhiqiang Wang ${ }^{4} \cdot$ A-Xing Zhu ${ }^{5,6,7}$. \\ Jing-ai Wang ${ }^{1,2}$
}

Received: 29 May 2014/Accepted: 6 May 2015/Published online: 16 May 2015

(C) Springer Science+Business Media Dordrecht 2015

\begin{abstract}
This paper presents a regionalized vulnerability curve-building approach to vulnerability and risk assessment of wheat subjected to drought that uses the Environmental Policy Integrated Climate (EPIC) model and statistical analysis. We defined wheat vulnerability as the degree to which a wheat production system is likely to experience yield loss due to a perturbation or drought hazard. Wheat vulnerability in a given region is thus the yield loss divided by the drought hazard index (DHI). By simulating a variety of wheat
\end{abstract}

Jing-ai Wang

jwang@bnu.edu.cn

Yaojie Yue

yjyue@bnu.edu.cn

Jian Li

276385041@qq.com

Xinyue Ye

xye5@kent.edu

Zhiqiang Wang

wangzhiqiang@ndrcc.gov.cn

A-Xing Zhu

azhu@wisc.edu

1 School of Geography, Beijing Normal University, Beijing 100875, China

2 State Key Laboratory of Earth Surface Processes and Resource Ecology, Beijing Normal University, Beijing 100875, China

3 Department of Geography, Kent State University, Kent, OH 44242, USA

4 National Disaster Reduction Center of China, Beijing 100100, China

5 Jiangsu Center for Collaborative Innovation in Geographical Information Resource Development and Application and School of Geography, Nanjing Normal University, Nanjing 210023, China

6 State Key Laboratory of Resources and Environmental Information System, Institute of Geographic Sciences and Natural Resources Research, Chinese Academy of Sciences, Beijing 100101, China

7 Department of Geography, University of Wisconsin-Madison, Madison, WI 53706, USA 
yield losses and associated DHIs, wheat drought vulnerability curves can be developed. We propose that agricultural systems be considered uniform within each wheat-planting region and different in different regions, according to territorial differentiation, when regionalized vulnerability curves are built. Based on this principle, a detailed regional crop calendar was improved, and optimized wheat varieties were refined that can differentiate agricultural systems within wheat-planting regions. The crop calendar was improved based on the assumption that local farmers have perfect knowledge in selecting sowing and harvesting dates. The wheat varieties were optimized by adjusting the genetic parameters of wheat in the EPIC model using the Shuffled Complex Evolution algorithm-University of Arizona (SCE-UA) method. Based on these improvements and innovations, the precision of most vulnerability curves was improved, and the curves were compared favorably to those observed in previous studies related to differences in the genetic character of wheat, the crop calendar, environmental conditions, and other relevant factors. Differences within each region were smaller than differences between regions. More detailed wheat vulnerability curves allow for the assessment of expected wheat yield loss and also allow for a high level of precision in an evaluation, at a variety of scales, of risk of wheat subject to drought. The proposed approach to building regionalized vulnerability curves has the potential to be the basis for crop drought vulnerability curves in different geographical areas at multiple scales.

Keywords Drought $\cdot$ Regionalized vulnerability curves $\cdot$ EPIC model $\cdot$ Wheat $\cdot$ China

\section{Introduction}

Vulnerability assessment is one of the key scientific issues in disaster risk research (Cutter 1996; Brooks 2003; Sullivan 2011). Vulnerability, which is defined as the degree to which a system is susceptible to and unable to cope with the adverse effects of climate change (McCarthy 2001), is an important concept in the study of risk and has been assessed in numerous case studies (Yoo et al. 2006; Field et al. 2012). Vulnerability is recognized as an inherent property of looseness when crops are threatened (Blaikie et al. 1994; McCarthy 2001; ISDR 2002; Turner et al. 2003a, b). More specifically, in agricultural drought research, vulnerability assessment attempts to calculate the loss or potential loss of crops or agricultural systems in order to identify factors causing vulnerability (Wilhelmi and Wilhite 2002; Zhang et al. 2013a, b). Thus, crop drought vulnerability assessment provides important scientific support in drought planning and mitigation (Ganji et al. 2006). Our research will build regionalized wheat drought vulnerability curves for wheat crops in China.

Vulnerability was assessed qualitatively when the term was first coined. Some widely applied qualitative methods are descriptive, for example in the RH (Turner et al. 2003a), PAR (Wisner 2004) and BBC models (Birkmann 2006). These methods provide the theoretical bases for quantitative vulnerability assessment. In agricultural drought vulnerability research, common quantitative disaster vulnerability assessment methods include a historical disaster loss data assessment, a multi-index evaluation method, and a hazard loss curve-based (vulnerability curve) assessment (Wang et al. 2013). Because the historical disaster loss method focuses on the disaster loss rate, it cannot reflect the process and mechanism of vulnerability formation and often suffers from insufficient data. The multi-index evaluation 
method uses the analytical hierarchy process (AHP), a fuzzy comprehensive evaluation, the Delphi method, the near method, and the projection pursuit technique to determine the weight of indexes (Wu et al. 2013). Statistical methods, such as empirical orthogonal function (Kim et al. 2011), expand gray relation analysis (Jiang et al. 2012), GIS (Wu et al. 2011), and other mathematical or technical methods, are also used in the multi-index evaluation method. However, the vulnerability estimate resulting from this method can only reflect the relative spatial distribution characteristics but cannot provide an actual value. Moreover, weight determination can be subjective. For example, the AHP method depends on expert evaluations to weigh the importance of factors, and the level of expertise fundamentally influences the final evaluation results. These shortcomings have limited the utility of vulnerability assessment and have led to increased interest in the vulnerability curve method.

A vulnerability curve (function) can be used to analyze the relationship between hazard intensity and loss of exposure. Many vulnerability curve studies have been reported related to such phenomena as floods (Dutta et al. 2003; Merz et al. 2004), earthquakes (Colombi et al. 2008), windstorms (Lee and Rosowsky 2005), and hail (Hohl et al. 2002). Wang et al. (2013) quantified wheat drought vulnerability. His research proposed an operational approach for assessing the physical vulnerability of two wheat varieties to drought using the Environmental Policy Integrated Climate (EPIC) model. Wheat yield loss was estimated using vulnerability curves that relate the water stress-based drought hazard index (DHI) to the yield loss rate under a particular level of drought intensity. However, this method, which uses the vulnerability curves of only two wheat varieties to assess vulnerability in China, is insufficient and requires a high degree of simplification, as it does not take territorial differentiation into account despite its large scale. Crop varieties, which are crucial parameters and have significant influence on wheat yield (Wang et al. 2005; Wu et al. 2009), have for the most part been ignored in previous studies. In addition, the crop calendar, which is obtained from statistical data, has a temporal resolution of 10 days, which is not precise enough and does not fit the model well as a crucial and sensitive parameter. Jia (2010) and Jia et al. (2012) also constructed regionalized vulnerability curves for corn according to China's corn regionalization, using the EPIC model, but the genetic parameters used in the model were the same for each corn-planting region, so the study found differences per corn-planting unit although the assessment was conducted according to corn-planting regions. Crop varieties, which are determined by genetic parameters, are the main cause of vulnerability difference among regions, a factor that cannot be neglected when using the EPIC model to assess crop vulnerability.

The main goal of our study is thus to propose an analytical procedure that can assess the vulnerability of wheat to drought while avoiding these shortcomings. Vulnerability is described here in terms of hazard loss curves, which describe the yield loss rate of a specific element at risk (i.e., a wheat field) compared with the DHI, which is based on water stress derived from the EPIC model. In the following sections, we describe the methodological framework on the basis of the EPIC model, using China as the research area. In addition, a model calibration and validation are performed. First, we calibrated the crop calendar and genetic parameters of each region. We then ran the EPIC model in each region in drought and optimal scenarios. Water stress and wheat yield, which are the model outputs, were used to obtain the DHI and yield loss separately. Last, we describe the analytical procedure used to develop vulnerability functions that can be used more broadly to evaluate wheat vulnerability in agricultural drought risk analyses conducted in China. 


\section{Method and data}

\subsection{Study area}

China is one of the top three wheat producers in the world. In 2011, the country's wheat production accounted for $16.8 \%$ of total world production, and China was ranked the top wheat producer worldwide (FAO 2011). Wheat is planted widely in China, which has 10 main wheat-planting regions: the South China Winter Wheat Region, the Southwest Winter Wheat Region, the Middle and Lower Yangtze Winter Wheat Region, the Huang-Huai Winter Wheat Region, the Qinghai-Tibet Spring and Winter Wheat Region, the North Winter Wheat Region, the Northwest Spring Wheat Region, the North Spring Wheat Region, the Xinjiang Winter and Spring Wheat Region, and the Northeast Spring Wheat Region (Zhao $2010 \mathrm{a}, \mathrm{b})$. However, drought is a dominant threat to wheat, representing up to $79.21 \%$ of all hazards to the crop (Zhang et al. 2013a, b). Most of the major wheat-planting areas, especially the Huang-Huai Winter Wheat and the North Winter Wheat regions, are under threat of drought hazard (He et al. 2011; Zhang et al. 2013a, b). It has been estimated that drought caused $1.58 \times 10^{7} \mathrm{t}$ in crop yield loss annually from 1950 to 2001 in China, accounting for $56.2 \%$ of loss from all natural disasters (Wang 2007). Moreover, drought frequency and potential yield loss are increasing due to global warming (Zhang et al. 2013a, b; Cao et al. 2014). A significant aggravation trend of meteorological drought in China from 1980s to 2000s has also been documented ( $\mathrm{Li}$ et al. 2014), especially for winter wheat-planting areas (Wang et al. 2012), which contribute more than $70 \%$ of wheat production. Wheat has thus been a consistent focus of agricultural drought research, and the increasingly aggravated drought in China makes understanding its vulnerability to drought even more critical. Regionalized wheat drought vulnerability curves could be the foundation of better assessments of wheat drought risk. Such research is necessary not only for formulating drought mitigation policy, but also for its potential as a methodology in other crop drought research.

Wheat planting in China has distinctive regional characteristics because of diverse natural conditions, planting systems, varieties, and production levels. Climate, for example, varies in terms of the wheat-growing season, yearly average temperature and yearly precipitation, which ranges from 100 to more than 350 days, $0{ }^{\circ} \mathrm{C}$ in Mohe to $23.8{ }^{\circ} \mathrm{C}$ in Hainan and from $100 \mathrm{~mm}$ inland to $2500 \mathrm{~mm}$ at the southeast coast, respectively. These significant regional differences in natural conditions lead to stark regional features for wheat planting, and are why wheat-planting zonation is the basis of this study. Of the 10 wheat-planting zones in China (Zhao 2010a), the Xinjiang Winter and Spring Wheat region was divided into the North Xinjiang Spring Wheat Region and the South Xinjiang Winter Wheat Region for this study, because the former plants mostly spring wheat, and the latter is suitable for winter wheat planting (Zhao 2010b). Note that the Qinghai-Tibet winter and spring wheat region is regarded as a spring wheat region because the spring wheat-planting area covers more than $66 \%$ of the region (Zhao 2010b). There are thus actually 11 typical wheat-planting zones for our EPIC model and analyses (Fig. 1).

\subsection{Methods}

The regionalized agricultural drought vulnerability curve is applicable to a vulnerability assessment of wheat affected by drought. We propose a new statistical method based on Tobler's First Law of Geography (Tobler 1970) via an EPIC model simulation. To model the regional impact of drought on wheat yield loss, we hypothesize that the wheat varieties 


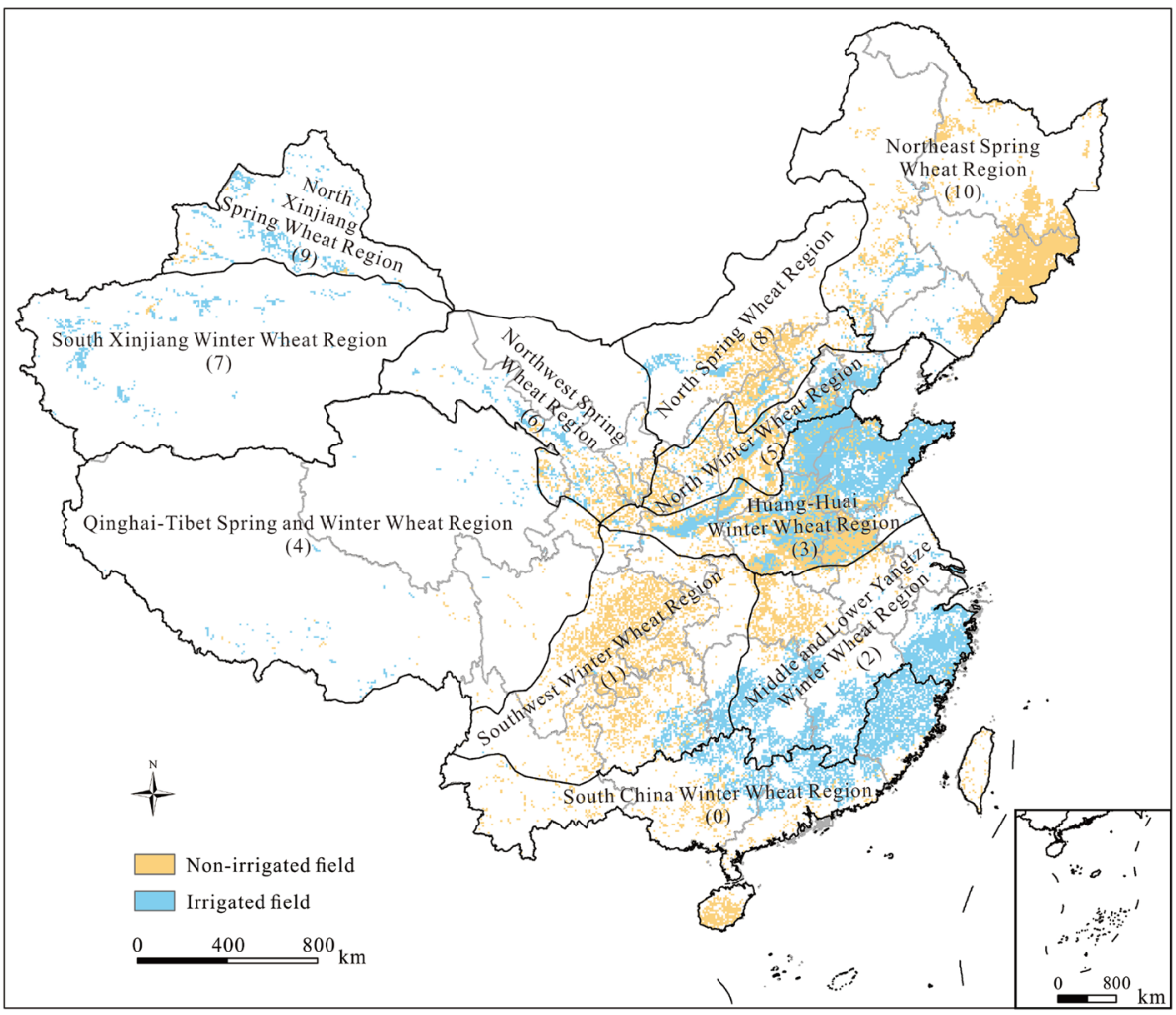

Fig. 1 Planting regionalization of wheat in China

and crop calendar vary across each wheat-planting region. Factors such as fertilization, tillage, or irrigation will remain the same for each station during the simulation periods. For the purpose of examining spatial differences in agricultural drought vulnerability, temporal differences, such as change in vulnerability with time due to the improvement of wheat varieties, are not considered.

Figure 2 illustrates the method's conceptual framework. The regional vulnerability curves are represented by two key indicators: yield loss and the drought index. The two indicators are obtained from the EPIC model. The drought index is bounded by the duration and intensity of water stress (WS), which is one of the output variables of the EPIC model. Before running the EPIC model, the genetic parameters and tillage date, which are the most sensitive parameters, must be calibrated. An agricultural system classification, which uses wheat varieties and management measures (crop calendar, fertilizer, pesticide, irrigation,

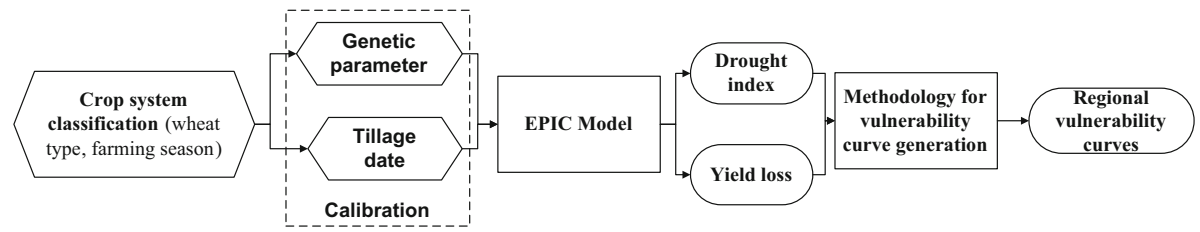

Fig. 2 Flowchart for the proposed framework of agricultural drought vulnerability analysis of wheat 
etc.), is used to define the capacity of each agricultural system. The agricultural systems are considered the same within each wheat-planting region and different in different regions.

\subsubsection{Agricultural drought index}

To simulate the influence of drought on wheat, effects other than drought should be eliminated through drought scenario settings. In the EPIC model, the stress caused by water, nutrients, temperature, aeration and radiation is estimated. The stresses range from 0 to 1 and affect plants in several ways. The stresses are considered in estimating constraints on biomass accumulation. The biomass constraint is the minimum level of water, nutrient, temperature, and aeration stresses (Williams 1995). The potential biomass is adjusted daily if any of the five plant stress factors is less than 1.0, using formula 1:

$$
\Delta B=\left(\Delta B_{\mathrm{p}}\right)(\mathrm{REG})
$$

where REG is the crop growth regulating factor (the minimum stress factor). In the simulation of agricultural drought, because the availability of water is one of the most critical among the factors that affect plant growth (Chaney 1981), the DHI should be based on water stress, and the other stresses should be eliminated. In Wang et al.'s study (2013), there are two scenarios: (1) wheat is planted with full nutrients and sufficient water; (2) wheat is planted with full nutrients and no irrigation (in other words, only rain-fed; the differences in yields were caused by water stress only). However, Wang's method could not completely eliminate the influence of temperature stress, so the yield loss rate was magnified (drought intensity was minimized equivalently according to formula 3) when temperature stress was more intensive than water stress (when TS $<\mathrm{WS}$ ). An assumption that wheat grows at an optimal temperature $\left(\mathrm{TG}_{i}\right.$ equals $T_{\mathrm{oj}}$ in formula 2$)$ during the growth periods in the drought simulation is thus made in order to eliminate temperature stress.

$$
\mathrm{TS}_{i}=\sin \left(\frac{\pi}{2}\left(\frac{\mathrm{TG}_{i}-T_{\mathrm{b} j}}{T_{\mathrm{o} j}-T_{\mathrm{bj}}}\right)\right)
$$

where TG is the average daily soil surface temperature in ${ }^{\circ} \mathrm{C} ; T_{\mathrm{b}}$ is the base temperature for $\operatorname{crop} j$, and $\mathrm{T}_{\mathrm{o}}$ is the optimal temperature for $\operatorname{crop} j$.

$$
\begin{aligned}
L_{y j} & =\frac{\mathrm{YLD} 1_{y}-\mathrm{YLD} 2_{y}}{\max \left(Y L D 1_{j}\right)} \\
& =\frac{(\mathrm{HI})\left(\sum_{i=1}^{n}\left(\Delta B_{\mathrm{p}}\right)_{i}\right)-(\mathrm{HI})\left(\sum_{i=1}^{n}\left(\Delta B_{\mathrm{p}}\right)_{i} \frac{\left(\mathrm{TS}_{i}+\mathrm{WS}_{i}-\left|\mathrm{TS}_{i}-\mathrm{WS}_{i}\right|\right)}{2}\right)}{(\mathrm{HI})\left(\sum_{i=1}^{n}\left(\Delta B_{\mathrm{p}}\right)_{i}\right)} \\
& \geq \frac{(\mathrm{HI})\left(\sum_{i=1}^{n}\left(\Delta B_{\mathrm{p}}\right)_{i}\right)-(\mathrm{HI})\left(\sum_{i=1}^{n}\left(\Delta B_{\mathrm{p}}\right)_{i}\left(\mathrm{WS}_{i}\right)\right)}{(\mathrm{HI})\left(\sum_{i=1}^{n}\left(\Delta B_{\mathrm{p}}\right)_{i}\right)}=L_{y j w \mathrm{~s}}
\end{aligned}
$$

where $L_{y j}$ is the loss rate of yield calculated in Wang's research; $L_{y j w s}$ is loss rate of yield caused only by water stress; $\left(\Delta B_{\mathrm{p}}\right)_{i}$ is the biomass increment in day $i$; $\mathrm{HI}$ is the harvest index; $\mathrm{TS}_{i}$ and $\mathrm{WS}_{i}$ are the temperature stress and water stress in day $i$, respectively.

The agricultural DHI is key to our method because the vulnerability curves are estimated in terms of DHI based on water stress versus the yield loss rate of wheat. WS represents the constraints on crop growth brought by water deficit. A close relationship between crop yield and WS has been established (Wu and Wilhite 2004). WS, as a daily output variable of the EPIC model, ranges from 0 to 1 . The lower the value, the stronger 
the water stress. In this study, the DHI built with WS is composed of the magnitude and duration of the stress, reflecting the intensity of drought hazard in the wheat-growing period. (formula 4).

$$
\mathrm{DHI}_{y j}=\frac{\sum_{i=1}^{n}\left(1-\mathrm{WS}_{i}\right)-\min \left(\mathrm{DHI}_{\mathrm{k}}\right)}{\max \left(\mathrm{DHI}_{k}\right)-\min \left(\mathrm{DHI}_{k}\right)}
$$

where $\mathrm{DHI}_{y j}$ refers to the agricultural DHI of $y$ year in station $j$; $\mathrm{WS}_{i}$ denotes the WS intensity of day $i$ when WS occurs; $n$ denotes the total days when there is water stress; and $\max / \mathrm{min}\left(\mathrm{DHI}_{k}\right)$ denotes maximum/minimum of the index of agricultural DHI of all years in all stations in region $k$.

In this manner, local soil conditions, wheat genetic characteristics, and cropping systems are included in the analysis, and water stress is determined by these parameters directly or indirectly. The water stress is calculated through formula 5 in the EPIC model (Williams 1995):

$$
\mathrm{WS}_{i}=\frac{\sum_{l=1}^{M} u_{i, l}}{E_{\mathrm{p} i}}
$$

where WS is the water stress factor; $u$ is the water use in layer $l$, and $E_{\mathrm{p} i}$ is the plant's potential water use on day $i$.

The related factors in formula 5 are calculated using formulas 6-8 (Williams 1995):

$$
\begin{aligned}
& E_{\mathrm{p}}=\frac{\left(\mathrm{E}_{0}\right)(\mathrm{LAI})}{3}, \quad 0 \leq \mathrm{LAI} \leq 3.0 \\
& E_{\mathrm{p}}=E_{0}, \quad \mathrm{LAI}>3.0
\end{aligned}
$$

where $E_{\mathrm{p}}$ is the predicted plant water evaporation; $E_{0}$ is the potential evaporation; and LAI is the leaf area index.

$$
\begin{aligned}
u_{\mathrm{p} l}= & \frac{E_{\mathrm{p} i}}{1-\exp (-\Lambda)}\left(1-\exp \left[-\Lambda\left(\frac{Z_{l}}{\mathrm{RZ}}\right)\right]-(1-\mathrm{UC})\left(1-\exp \left[-\Lambda\left(\frac{Z_{l-1}}{\mathrm{RZ}}\right)\right]\right)\right) \\
& -\mathrm{UC} \sum_{k=1}^{l-1} u_{k}
\end{aligned}
$$

where $u_{\mathrm{p} l}$ is the potential water use rate for layer $l$; RZ is the root zone depth; $Z_{l}$ is the depth of layer $l ; \Lambda$ is a water use distribution parameter; and UC is the water deficit compensation factor.

$$
\begin{aligned}
& u_{l}=u_{\mathrm{p} l} \exp \left(5\left(\frac{4\left(\mathrm{SW}_{l i}-\mathrm{WP}_{l}\right)}{\left(\mathrm{FC}_{l}-\mathrm{WP}_{l}\right)}-1\right)\right), \quad \mathrm{SW}_{l}<\frac{\mathrm{FC}_{l}-\mathrm{WP}_{l}}{4}+\mathrm{WP}_{l} \\
& u_{l}=u_{\mathrm{p} l}, \quad \mathrm{SW}_{l} \geq \frac{\mathrm{FC}_{l}-\mathrm{WP}_{l}}{4}+\mathrm{WP}_{l}
\end{aligned}
$$

where $\mathrm{SW}_{l i}$ is the soil water content in layer $l$ on day $i$ and FC and WP are the soil water content at field capacity and wilting point for layer $l$, respectively.

\subsubsection{Vulnerability curve establishment}

The modified scenario settings from Wang et al. (2013) are wheat planted with full nutrients, optimal temperature and enough water (through irrigation settings in the EPIC 
model) in the optimal scenario (YLD1) and wheat planted with full nutrients, optimal temperature, and non-irrigation (rain-fed) in the drought scenario (YLD2). Thus, the difference between the two revised scenarios should result from the effect of water stress alone. The yield loss rate is calculated using formula 9, and the corresponding DHI is calculated under the drought scenario through formula 4 .

$$
L_{y j}=\frac{\mathrm{YLD}_{y}-\mathrm{YLD} 2_{y}}{\max \left(\mathrm{YLD} 1_{j}\right)}
$$

where $L_{y j}$ is the loss rate of yield of $y$ year in station $j$; YLD1 $1_{y}$ and YLD2 $y$ are the yield of $y$ year under optimal and drought scenarios, respectively; and max (YLD1 $1_{j}$ ) is maximum annual yield of station $j$.

However, another problem arises when scenario settings in some regions have vulnerability curves with many points that have a yield loss rate reaching nearly to 1 (Fig. 7). This is because the precipitation in some or most stations of these regions is minimal, and in the drought scenario, the WS can reach below 0.01 . When this is the case, wheat will almost completely die. To address the problem, just enough irrigation is provided in the drought scenario to prevent the wheat from dying, and at the same time to prevent the drought intensity from being overly influenced.

Previous studies have found that crop yield loss and drought intensity have a logistic relationship (Jia et al. 2012; Wang et al. 2013). To generate the vulnerability curves (hazard-loss curves), a regression analysis method is used, requiring enough sample points. The number of stations in each region allows for the generation of a large number of scenarios of drought hazard intensity, ensuring the precision of the vulnerability curves.

\subsubsection{Model calibration and validation}

Model calibration helps to verify the wheat varieties, which are determined by genetic parameters in the EPIC model and management measures (mainly the crop calendar and other measures using default values) that are used for the crop system classification of the wheat-planting regions. The sowing and harvesting dates (especially the sowing date), which are highly sensitivity parameters related to crop yield (Wu et al. 2009), are different for each region because of the variation in environmental conditions. Thus, the determination of the wheat sowing and harvesting date for each region is completed first. Our model assumes that local farmers have perfect knowledge in selecting sowing and harvesting dates (Liu et al. 2008). In simulating the impact of drought, the model finds proper planting and harvest dates for optimized total yield during the simulation period. The alternative date is determined using the earliest sowing day, sowing date range, and duration (Table 1: Zhao 2010a, b).

Model calibration aims to determine a set of genetic wheat parameters that could represent the physiological characteristics of each wheat region. Calibration is completed using the Shuffled Complex Evolution Algorithm-University of Arizona (SCE-UA), which is an automatic calibration method proposed by Duan et al. (1992). The simulations through SCE-UA are regarded as valuable as they sample the entire parameter space, with a focus on solutions near the optimum (Xu et al. 2013). Based on previous studies (Wang et al. 2005; Wu et al. 2009; Liu 2009), the following six parameters were selected for calibration: (1) potential radiation use efficiency (WA), (2) harvest index (HI), (3) point in the growing season when leaf area begins to decline due to leaf senescence (DLAI), (4) normal fraction of $\mathrm{N}$ in crop biomass at mid-season (BN2), (5) potential heat unit (PHU), 
Table 1 Sowing and harvesting dates used for calibration (refer to Zhao 2010a, b)

\begin{tabular}{|c|c|c|c|c|}
\hline \multirow[t]{2}{*}{ Region } & \multicolumn{2}{|c|}{ Earliest sowing day } & \multirow[t]{2}{*}{ Sowing date range } & \multirow[t]{2}{*}{ Duration } \\
\hline & Month & Day & & \\
\hline 0 & 10 & 30 & 21 & $125-150$ \\
\hline 1 & 8 & 20 & 82 & $175-250$ \\
\hline 2 & 10 & 21 & 30 & $200-225$ \\
\hline 3 & 9 & 11 & 39 & $230-250$ \\
\hline 4 & 3 & 21 & 30 & $130-190$ \\
\hline 5 & 9 & 11 & 39 & $250-280$ \\
\hline 6 & 3 & 11 & 30 & $120-150$ \\
\hline 7 & 9 & 21 & 19 & $245-265$ \\
\hline 8 & 3 & 11 & 40 & $110-120$ \\
\hline 9 & 4 & 1 & 19 & $90-100$ \\
\hline 10 & 3 & 11 & 50 & $100-120$ \\
\hline
\end{tabular}

In column Region: 0: South China Winter Wheat Region; 1: Southwest Winter Wheat Region; 2: Middle and Lower Yangtze Winter Wheat Region; 3: Huang-Huai Winter Wheat Region; 4: Qinghai-Tibet Spring and Winter Wheat Region; 5: North Winter Wheat Region; 6: Northwest Spring Wheat Region; 7: Xinjiang Winter Wheat Region; 8: North Spring Wheat Region; 9: North Xinjiang Spring Wheat Region; 10: Northeast Spring Wheat Region, which have the same meaning in the following tables and figures

and (6) crop parameter control leaf area growth of the crop under non-stressed condition (DLP2), which are the most sensitive parameters for crop yield in the EPIC model. The calculation procedure and parameter settings of the algorithm are based on Duan et al. (1993, 1994). The objective function is $F=\operatorname{Abs}\left(1-d_{y}\right)$, where $d_{y}$ represents the coefficient of determination. The convergence tolerance of the objective function and parameter iteration step length are 0.1 and $10^{-5}$, respectively. The calibration will stop if convergence is not achieved after 5000 iterations. The boundary values of a crop's genetic parameters are listed in Table 2. A specific station with relative consecutive time series is selected for each region with the observed wheat yield data. The other stations' data for each region are used for validation. The following parameters are used to measure the precision of the model calibration and validation (Gaiser et al. 2010).Mean relative error

$$
\operatorname{MRE}=\frac{1}{n} \sum_{i=1}^{n} \frac{\left(\hat{y}_{i}-y_{i}\right)}{y_{i}}
$$

Table 2 Calibrated parameter boundary values

\begin{tabular}{|c|c|c|c|c|}
\hline \multirow[t]{2}{*}{ Parameters } & \multicolumn{2}{|l|}{ Default } & \multicolumn{2}{|l|}{ Range } \\
\hline & Spring wheat & Winter wheat & Lower range & Higher range \\
\hline WA & 30.0 & 35.0 & 30 & 45 \\
\hline HI & 0.5 & 0.5 & 0.45 & 0.6 \\
\hline DLAI & 0.60 & 0.60 & 0.1 & 1 \\
\hline BN2 & 0.0250 & 0.0230 & 0.0134 & 0.06 \\
\hline PHU & 1500 & 1500 & 1200 & 2400 \\
\hline DLP2 & 49.950 & 50.950 & 10 & 100 \\
\hline
\end{tabular}


Model efficiency

$$
\mathrm{MEF}=\frac{\sum_{i=1}^{n}\left(y_{i}-\bar{y}\right)^{2}-\sum_{i=1}^{n}\left(y_{i}-\hat{y}_{i}\right)^{2}}{\sum_{i=1}^{n}\left(y_{i}-\bar{y}\right)^{2}}
$$

Root-mean-square error

$$
\operatorname{RMSE}=\frac{100}{\bar{y}} \sqrt{\frac{1}{n} \sum_{i=1}^{n}\left(\hat{y}_{i}-y_{i}\right)^{2}}
$$

where $n$ is the sample number; $y$ is the observed yield; $\hat{y}$ is the predicted maize yield; and $\bar{y}$ is the mean of the observed values. Values of mean relative error (MRE) close to zero indicate small differences between the predicted and measured mean crop yield, which thus indicate little systematic deviation or bias in the entire dataset. The same conclusion can be drawn if the model efficiency (MEF) is close to one. Values of absolute error or root-mean-square error (RMSE) close to zero indicate the precision and reliability of the prediction for single-yield estimation points.

\subsection{EPIC model and inputs}

The EPIC model was developed from the Erosion Productivity Impact Calculator model (Williams et al. 1984), which was originally developed to assess the effect of soil erosion on crop productivity. Because of its advantage in simulating crop growth processes based on daily step (Williams et al. 1989; Sharpley and Williams 1990), the EPIC model has been widely used in crop drought research, such as building wheat drought vulnerability curves (Wang et al. 2013), maize drought risk assessment (Jia 2010; Jia et al. 2012; Yin et al. 2014), and crop irrigation management (Rinaldi 2001). For simulating the wheat growth process, the model inputs include meteorological data, soil data, and agricultural data such as crop yield used for model calibration and validation (Table 3).

\begin{tabular}{|c|c|c|}
\hline Data name & Content & Source \\
\hline Meteorological data & $\begin{array}{l}\text { Daily recorded dada, } 1950-2011, \\
752 \text { stations, includes precipitation, } \\
\text { temperature, radiation, wind speed } \\
\text { and relative humidity etc. }\end{array}$ & $\begin{array}{l}\text { China meteorological data sharing } \\
\text { service system of China } \\
\text { Meteorological Administration } \\
\text { (http://cdc.cma.gov.cn/gx/web/ } \\
\text { sjfljs.jsp) }\end{array}$ \\
\hline $\begin{array}{l}\text { Spatial distribution of soil } \\
\text { type }\end{array}$ & 1:1,000,000 digital soil map of China & $\begin{array}{l}\text { Institute of Soil Science, Chinese } \\
\text { Academy of Science }\end{array}$ \\
\hline Soil properties & $\begin{array}{l}\text { Soil layers, texture data, and organic } \\
\text { carbon etc. }\end{array}$ & $\begin{array}{l}\text { Chinese Soil Genus Records } \\
\text { (National Soil Survey Office } \\
\text { National Soil Survey Office 1994) }\end{array}$ \\
\hline Wheat yield data & $\begin{array}{l}\text { Annual wheat yield data recorded by } \\
\text { agro-meteorological experimental } \\
\text { stations of China Meteorological } \\
\text { Administration, 2000-2011, } 175 \\
\text { stations }\end{array}$ & $\begin{array}{l}\text { China meteorological data sharing } \\
\text { service system of China } \\
\text { Meteorological Administration } \\
\text { (http://cdc.cma.gov.cn/gx/web/ } \\
\text { sjljs.jsp) }\end{array}$ \\
\hline Wheat regionalization map & $\begin{array}{l}\text { Wheat-planting regionalization map } \\
\text { of China }\end{array}$ & $\begin{array}{l}\text { Data sharing net of Chinese } \\
\text { Academy of Agricultural Sciences } \\
\text { (http://www.caas.net.cn/sjk/54019. } \\
\text { shtml) }\end{array}$ \\
\hline
\end{tabular}

Table 3 Major data sources 
Daily routine meteorological data were obtained from 752 China Meteorological Administration stations, including daily maximum and minimum temperature, wind speed, humidity, and precipitation, and were used in the model processing. Daily solar radiation data were available from 122 China Meteorological Administration stations. The solar radiation data at other stations were estimated based on sunshine duration data using the Angstrom-Prescott model (Angstrom 1924; Prescott 1940) as used in our previous studies (Wang et al. 2012; 2013). The soil data include soil type and soil properties. The digital soil map of China $(1: 1,000,000)$ was produced by the Institute of Soil Science and the Chinese Academy of Science (Shi et al. 2004). Soil property data, including the physical and chemical properties of soil, such as the number of soil layers, soil albedo, bulk density, clay content, soil $\mathrm{pH}$, and soil organic matter, were extracted from Chinese Soil Genus Records (National Soil Survey Office 1994). Both of these data sources have been used in our previous research (Jia 2010; Wang et al. 2012; Jia et al. 2012; Wang et al. 2013). Crop yield data provided by 386 agro-meteorological experimental stations of the China Meteorological Administration, among them 175 stations (37 stations that record spring wheat yield, 141 stations that record winter wheat yield, and three of these stations that record both) had annual wheat yield records from 2000 to 2011 . These wheat yield data have been validated as meeting the needs of EPIC model calibration and validation (Wang et al. 2012, 2013).

\section{Results}

\subsection{EPIC model parameters}

The proposed method allowed us to establish a set of optimized EPIC model parameters for wheat yield simulation, including sowing and harvesting date and genetic parameters. The best sowing and harvesting date for each station in each region is listed in Table 4 . The genetic parameters of wheat for each wheat region are then determined and are listed in Table 5.

The derived crop calendar, especially the sowing date, can eliminate the "stress" of the crop calendar (otherwise it may lead to a yield decline), because it is a better fit for the model's operation, compared with the statistical crop calendar (Wang et al. 2012). In addition, it incorporates the farmers' capacities to cope with climate change, which

Table 4 Best sowing and harvesting date in each wheat region

\begin{tabular}{llllll}
\hline \multirow{2}{*}{ Region } & \multicolumn{2}{l}{ Sowing date } & & \multicolumn{2}{l}{ Harvesting date } \\
\cline { 2 - 3 } & Earliest & Latest & & Earliest & Latest \\
\hline 0 & 30-Oct & 18-Nov & & 29-Mar & 17-Apr \\
1 & 20-Aug & 8-Nov & & 27-Apr & 16-Jul \\
2 & 21-Oct & 18-Nov & & 3-Jun & 1-Jul \\
3 & 11-Sep & 18-Oct & & 19-May & 25-Jun \\
4 & 21-Mar & 18-Apr & & 27-Sep & 25-Oct \\
5 & 11-Sep & 18-Oct & & 18-Jun & 25-Jul \\
6 & 11-Mar & 8-Apr & & 8-Aug & 5-Sep \\
7 & 21-Sep & 8-Oct & & 13-Jun & 30-Jun \\
8 & 11-Mar & 18-Apr & & 9-Jul & 16-Aug \\
9 & 1-Apr & 18-Apr & & 10-Jul & 27-Jul \\
10 & 11-Mar & 28-Apr & & 9-Jul & 26-Aug \\
\hline
\end{tabular}


Table 5 Optimized genetic parameters in each wheat region

\begin{tabular}{lllllll}
\hline \multirow{2}{*}{ Region } & \multicolumn{6}{l}{ Crop parameters } \\
\cline { 2 - 7 } & WA & HI & DLAI & BN2 & PHU & DLP2 \\
\hline 0 & 33.7 & 0.46 & 0.54 & 0.0441 & 2341 & 84.079 \\
1 & 30.8 & 0.45 & 0.37 & 0.0260 & 1586 & 76.166 \\
2 & 30.2 & 0.45 & 0.87 & 0.0205 & 1990 & 79.678 \\
3 & 30.0 & 0.45 & 0.54 & 0.0495 & 1706 & 81.652 \\
4 & 45.0 & 0.60 & 0.44 & 0.0289 & 1336 & 30.999 \\
5 & 43.7 & 0.59 & 0.62 & 0.0378 & 1209 & 81.414 \\
6 & 30.1 & 0.50 & 0.73 & 0.0543 & 1924 & 78.468 \\
7 & 44.2 & 0.50 & 0.33 & 0.0594 & 1211 & 38.781 \\
8 & 35.4 & 0.50 & 0.53 & 0.0392 & 1685 & 69.078 \\
9 & 36.0 & 0.51 & 0.38 & 0.0415 & 1201 & 71.930 \\
10 & 30.6 & 0.46 & 0.44 & 0.0298 & 2345 & 67.613 \\
\hline
\end{tabular}

improves decision making when profiling the differential vulnerability of each wheatplanting region (Turner et al. 2003a), by adjusting the sowing and harvesting date for optimized yield (Liu et al. 2008).

\subsection{Regional wheat yield simulation}

Figure 3 illustrates the simulated and observed yield data for the stations selected for calibration. Most regions satisfied the termination criterion of objective function; however, some regions did not. In order to assess the results of a given simulation, a graphic comparison between the simulated and observed wheat yields is depicted in Fig. 4 for each region. The indices for testing validation performance are provided in Table 6 .

The simulated yields and observed yields for most regions are comparable (Fig. 3). The figure shows that the slopes of the trend lines are close to 1 , and the $R^{2}$ is relatively high (Fig. 4). The MRE and RMSE are small (Table 6). The values of MEF also indicate relatively good validation results (most are close to 1 ). This indicates that the simulation results are acceptable.

In regions 0,8 and 10 , however, the fit is lower than for other regions. In regions 0 and 10 in particular, the slope and $R^{2}$ are close to 0 . The RMSE and MRE are higher than they are in other regions, and the MEF values are much lower (Table 6). These results may have different causes. In regions 0 and 10, the points are quite scattered, indicating that the wheat-planting regionalization is not accurate enough to differentiate the wheat-growing systems, so that the wheat yield in regions 0 and 10 have a clear difference. In fact, within these two regions, the wheat varieties still have relatively big differences. Figure 4 (region 0 ) shows that the points clearly converge at two centers, which should lead the regions to become further regionalized. Because the points are evenly distributed on both sides of the 1:1 line, however, the result is acceptable for estimating regional regularities. In region 8 , the poor fit is due to insufficient observed data. There are only two observed data points, and the RMSE, MRE, and MEF suggest relatively good model performance. But the precision of the validation is uncertain due to insufficient data.

\subsection{Wheat vulnerability curves for China}

Figure 5 illustrates the derived sets of vulnerability curves for the 11 wheat regions. Most curves fit very well, with an $R^{2}$ close to 1 . In most winter wheat regions, the curves are 
closer to an S shape (i.e., regions 0, 1, 3, 5, and 7) as Wang et al. (2013) have pointed out. Most curves of spring wheat regions are more linear (i.e., regions 4, 8, and 10). Wang et al. (2013) found that a vulnerability curve imposes a magnification or reduction effect on the disaster risk in different sections. In regions $0,3,5,7$ and 9, there are three sections for which the vulnerability curve poses a reduction effect on the disaster risk with lower and higher DHI and a magnification effect with moderate DHI. In the other regions, the
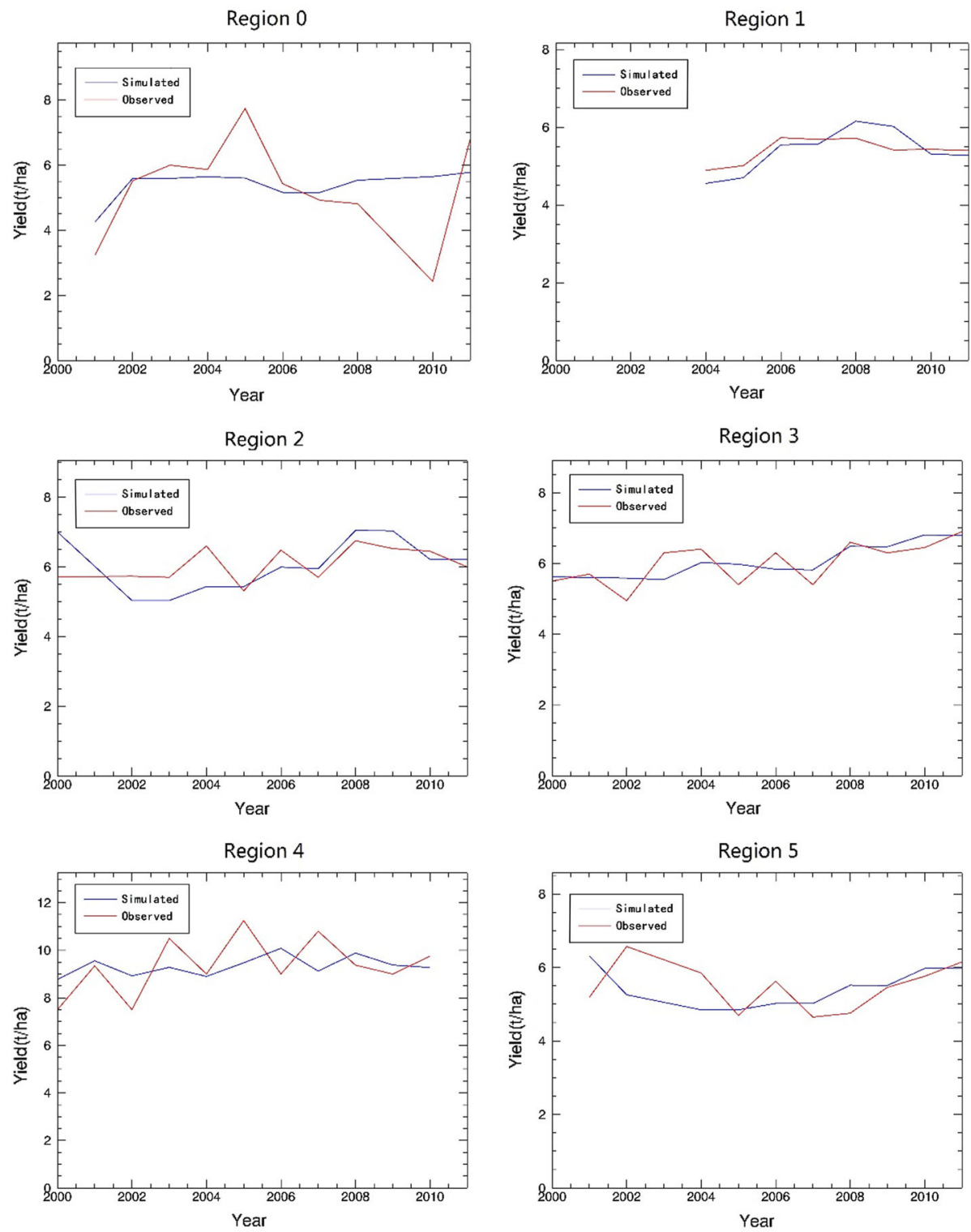

Fig. 3 Yearly yield simulations during calibration period in each wheat region, and $\mathbf{a}-\mathbf{k}$ for regions $0-10$, respectively 

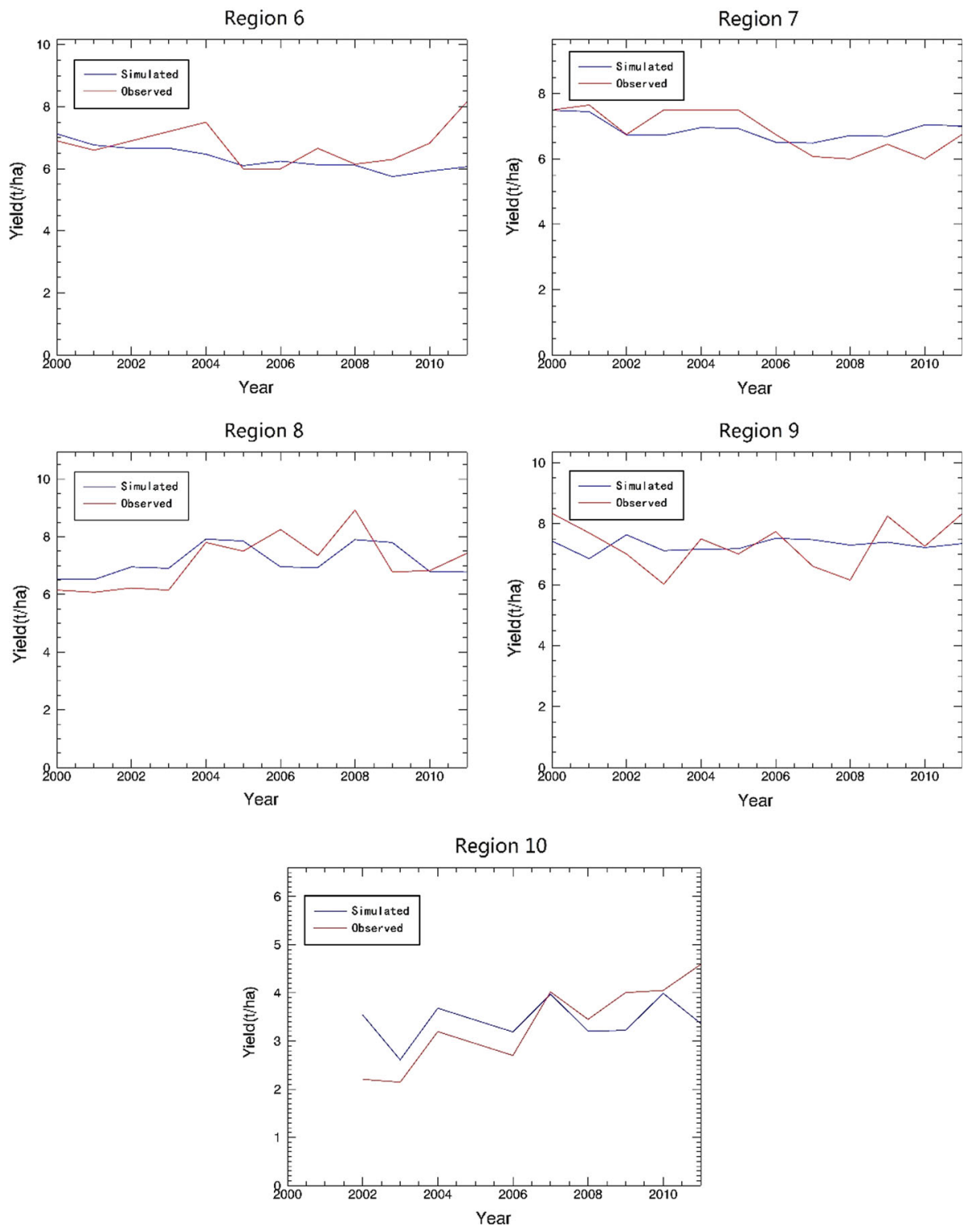

Fig. 3 continued

vulnerability curve poses only a reduction effect. This indicates that regions $0,3,5,7$ and 9 are generally more vulnerable than the other regions.

These vulnerability curves, compared with Wang et al.'s (2013) two vulnerability curves for wheat, have better precision, because the differences in the relevant parameters, such as the wheat's genetic character, the crop calendar, and environmental conditions, within each region are smaller than the differences among regions, so the points are more convergent. The differences between regions are clear, which can be seen from both the 
figures and the functions of the vulnerability curves (Fig. 6; Table 7). The derived wheat vulnerability curves for agricultural drought, which are based on the regionalization of wheat planting in China, take wheat varieties (genetic properties) and crop calendars (agricultural management) into account and can better demonstrate the regional regularity of wheat's vulnerability to drought and risk in China or in any particular wheat-planting region than do curves that do not consider regional disparities.
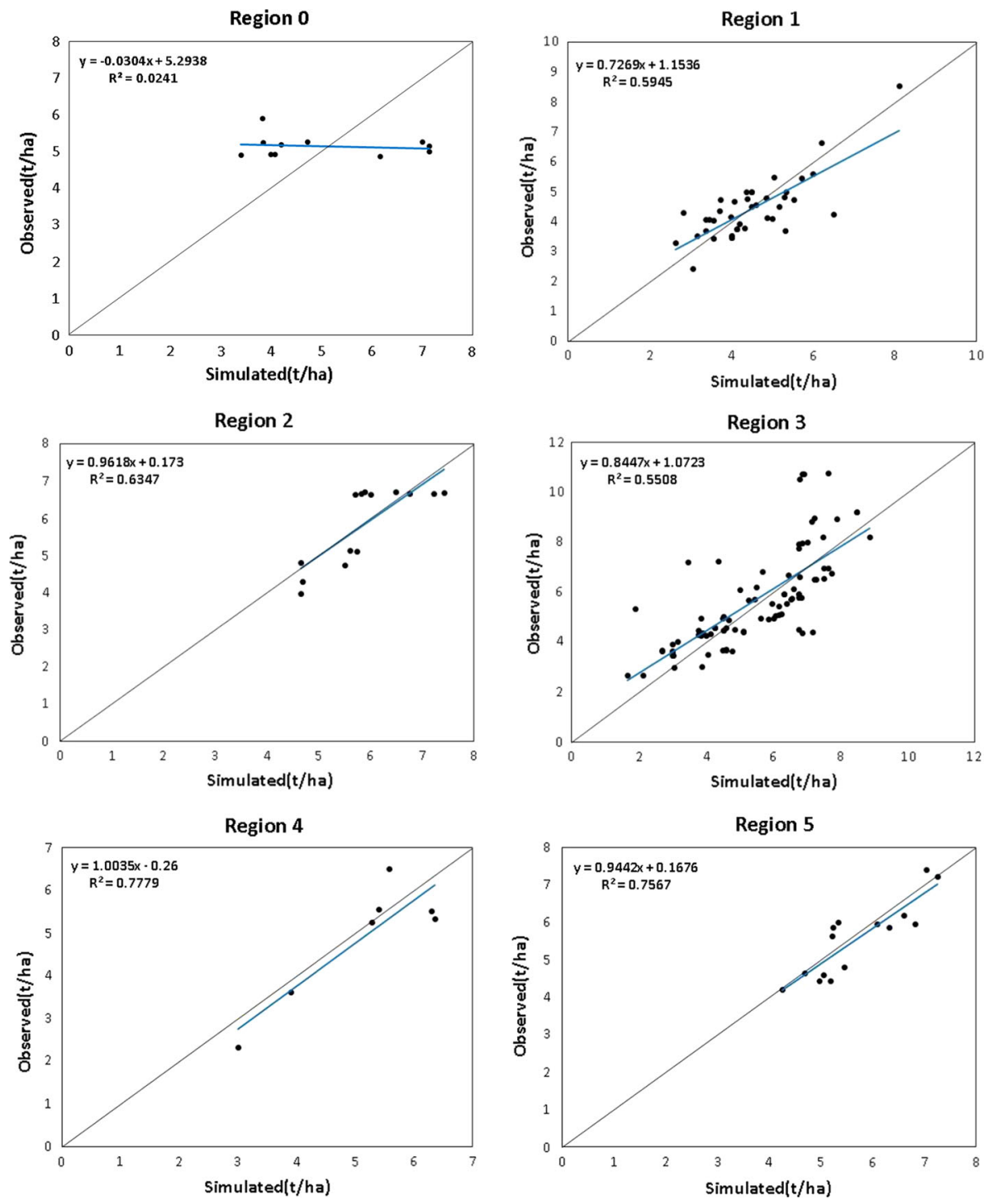

Fig. 4 Comparison between simulated wheat yields and observed yields in each region 

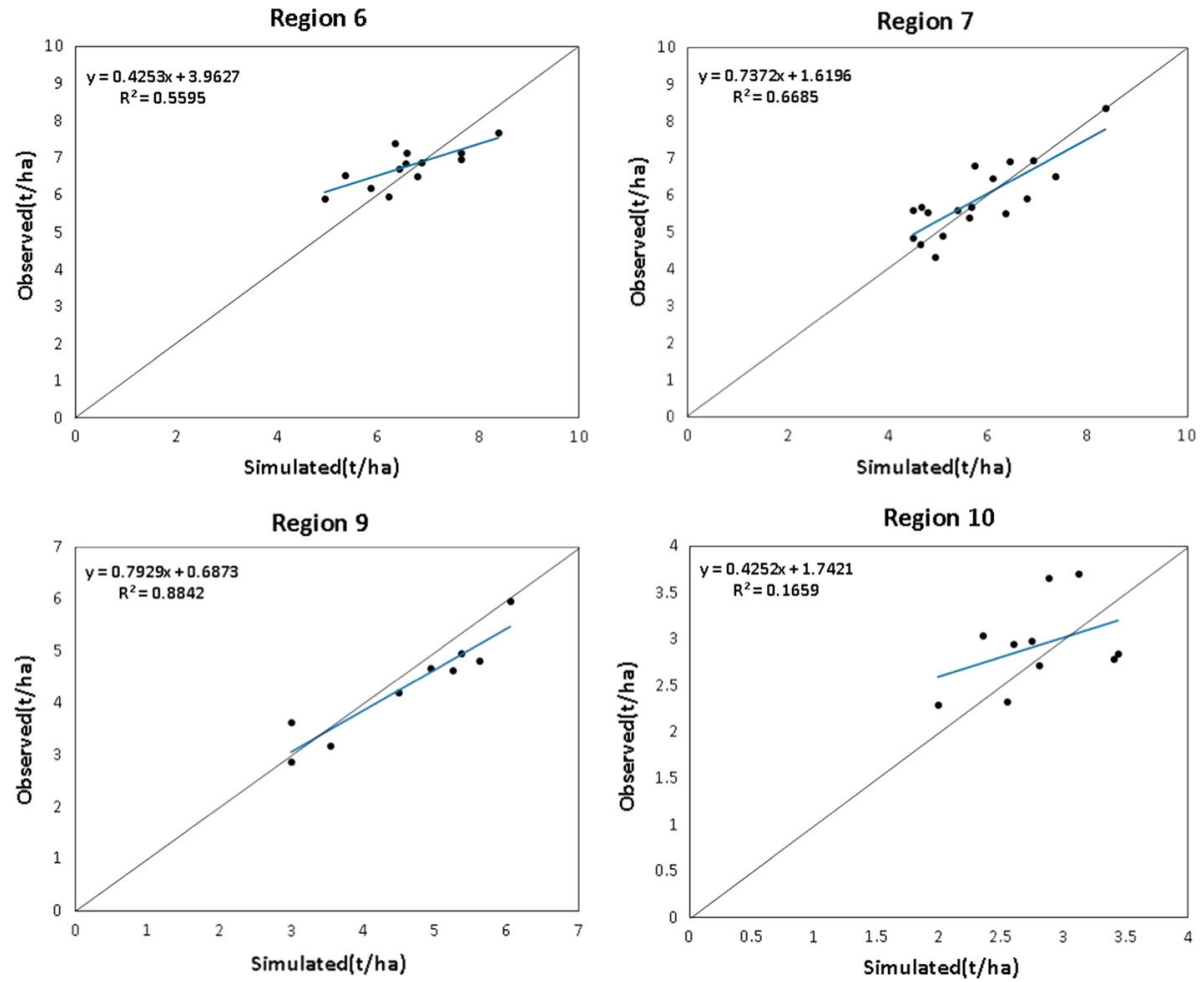

Fig. 4 continued

Table 6 Statistical index for validation

\begin{tabular}{lrlcll}
\hline Region & Slope & $R^{2}$ & RMSE $(\%)$ & MRE & MEF \\
\hline 0 & -0.03 & 0.02 & 29.58 & 0.28 & 0.10 \\
1 & 0.73 & 0.59 & 10.74 & 0.11 & 0.80 \\
2 & 0.96 & 0.63 & 10.61 & 0.10 & 0.46 \\
3 & 0.84 & 0.55 & 14.16 & 0.14 & 0.79 \\
4 & 1.00 & 0.78 & 12.93 & 0.11 & 0.67 \\
5 & 0.94 & 0.76 & 8.80 & 0.07 & 0.68 \\
6 & 0.43 & 0.56 & 9.82 & 0.09 & 0.49 \\
7 & 0.74 & 0.67 & 10.86 & 0.09 & 0.65 \\
8 & 1.80 & 1.00 & 7.28 & 0.07 & 0.88 \\
9 & 0.79 & 0.88 & 10.12 & 0.09 & 0.82 \\
10 & 0.17 & 0.17 & 17.80 & 0.16 & 0.35 \\
\hline
\end{tabular}

\section{Discussion}

\subsection{Calibration and validation of the EPIC model}

Crop model calibration and validation is a challenging task because of the many possible uncertainties. One source of uncertainty is the lack of agricultural management data, such 
as fertilization, irrigation, tillage, and pesticide data. We relied mostly on default values provided by the EPIC model for our agricultural management data, as is common (Wang et al. 2013). This is one reason that the simulated yield may not match the observed yield at peak simulation (Fig. 3). In addition to agricultural management factors, factors such as the sowing and harvesting date (Wu et al. 2009), potential radiation use efficiency (WA),
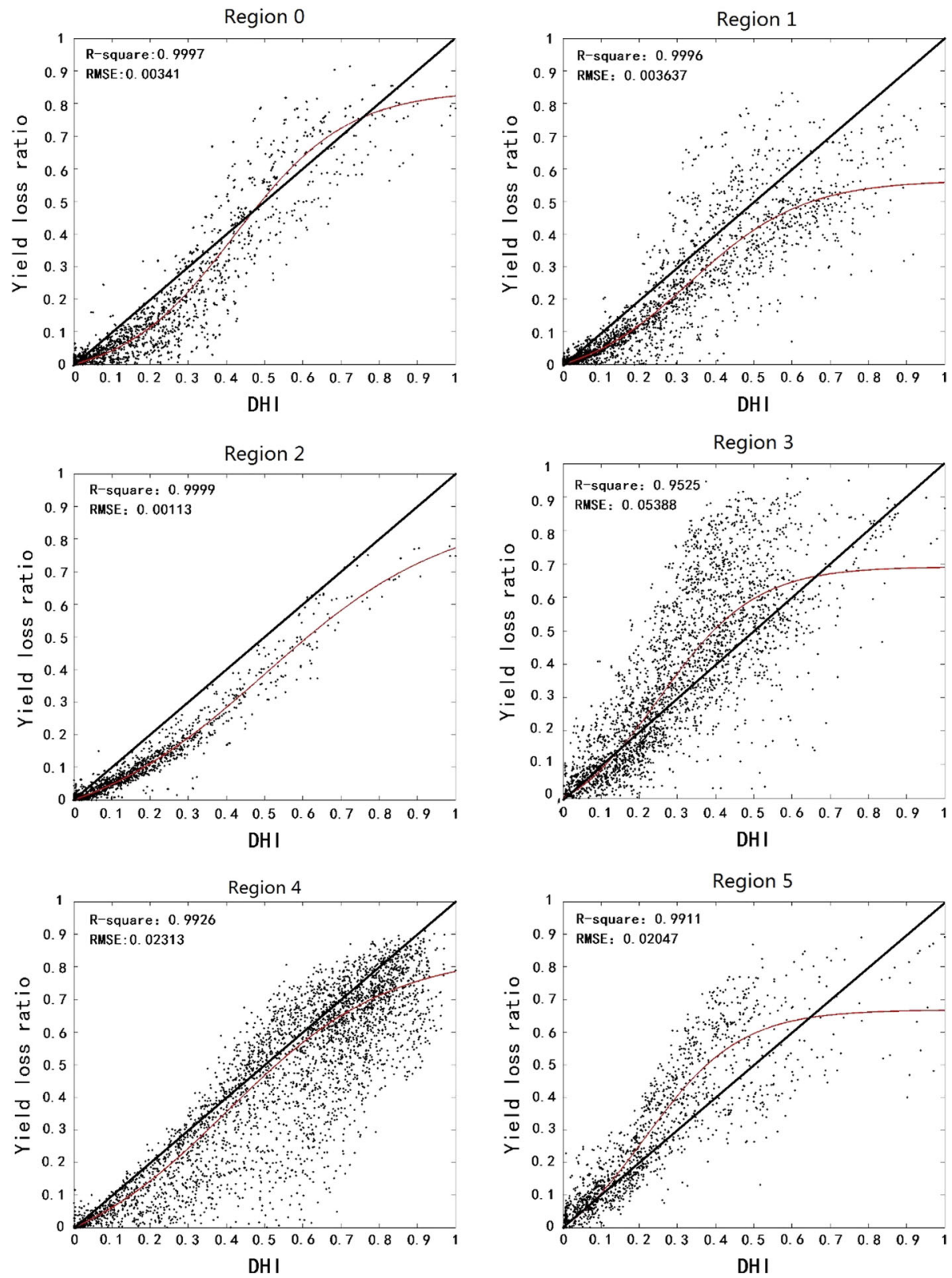

Fig. 5 Vulnerability curves of regions $0-10$, and $\mathbf{a}-\mathbf{k}$ for regions $0-10$, respectively 

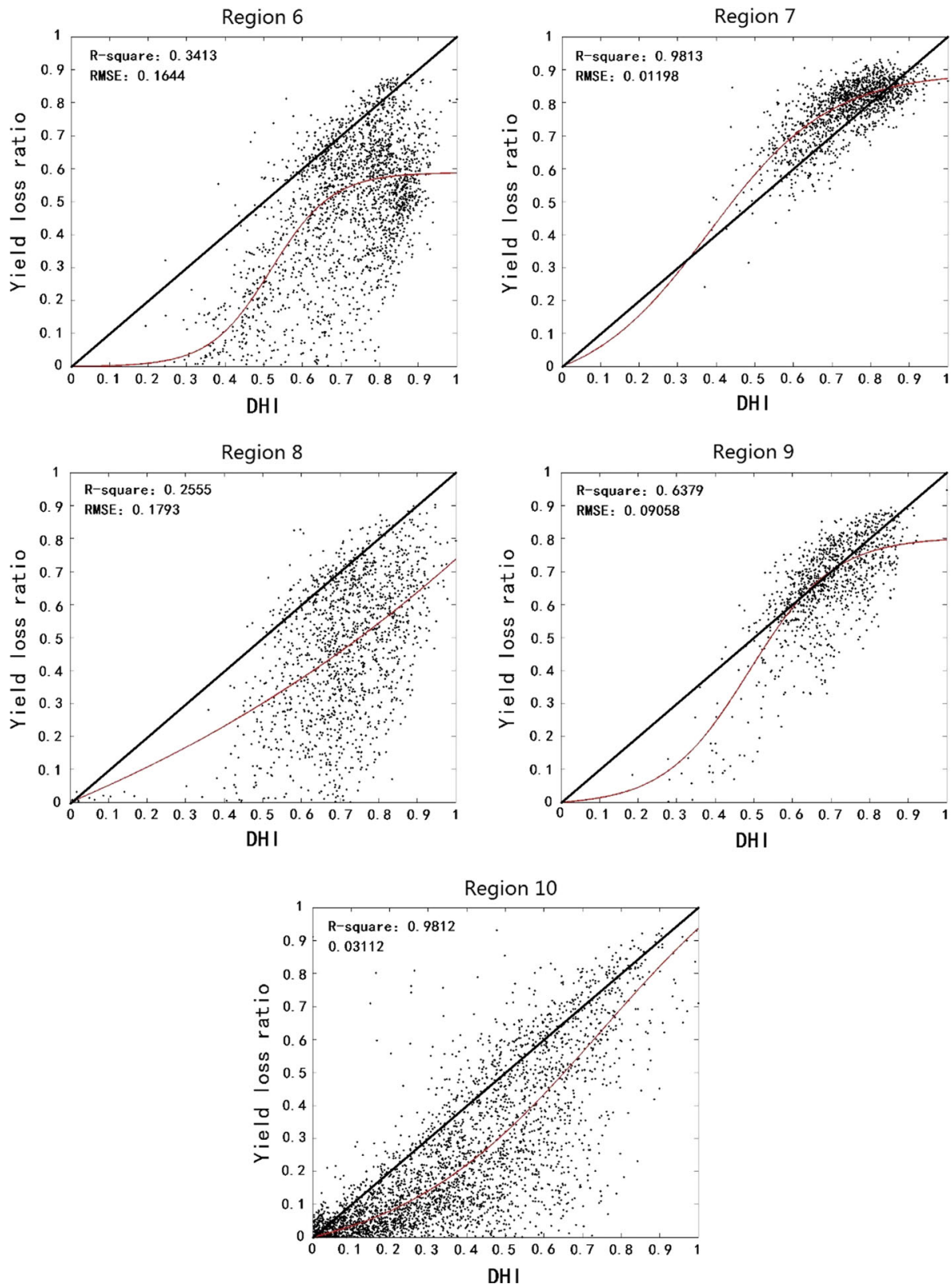

Fig. 5 continued

harvest index (HI), the point in the growing season at which leaf area begins to decline due to leaf senescence (DLAI), the normal fraction of $\mathrm{N}$ in crop biomass at mid-season (BN2), potential heat unit (PHU), and crop parameter control of leaf area growth in a crop under a non-stressed condition (DLP2) (Wang et al. 2005; Wu et al. 2009; Liu 2009), have significant impacts on wheat yield, whether in reality or in model processing, due to the 


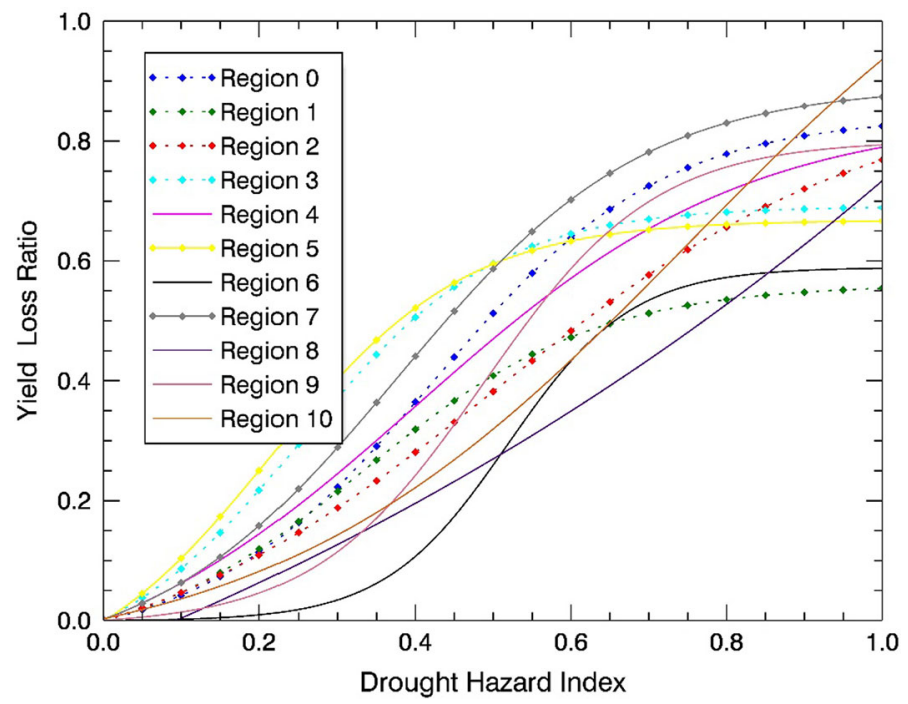

Fig. 6 Vulnerability curves of all regions; dotted lines with circles represent winter wheat regions; solid lines represent spring wheat regions

Table 7 Function of vulnerability curves of each wheat region

\begin{tabular}{|c|c|}
\hline Region & Function of vulnerability curves \\
\hline 0 & $L_{0}=\frac{0.89}{1+17.52 e^{-6.79 \mathrm{DH} \mathrm{I}_{0}}}-0.048$ \\
\hline 1 & $L_{1}=\frac{0.62}{1+9.57 e^{-6.76 \mathrm{DH}} \mathrm{I}_{1}}-0.059$ \\
\hline 2 & $L_{2}=\frac{0.99}{1+8.06 e^{-4.15 \mathrm{DHI}}}-0.110$ \\
\hline 3 & $L_{3}=\frac{-0.78}{1+0.13 e^{8.02 \mathrm{DH} I_{3}}}+0.691$ \\
\hline 4 & $L_{4 s}=\frac{0.97}{1+6.65 e^{-4.72 \mathrm{DH}_{4}}}-0.126$ \\
\hline 5 & $L_{5}=\frac{-0.79}{1+0.18 e^{7.99 \mathrm{DH}} \mathrm{H}_{5}}+0.668$ \\
\hline 6 & $L_{6}=\frac{0.59}{1+685.60 e^{-12.59 \mathrm{DHI}_{6}}}-0.001$ \\
\hline 7 & $L_{7}=\frac{-0.97}{1+0.09 e^{6.37 \mathrm{DH} l_{7}}}+0.892$ \\
\hline 8 & $L_{8}=\frac{-23.04}{1+0.03 e^{0.81 \mathrm{IDH}} 8}+22.418$ \\
\hline 9 & $L_{9}=\frac{0.81}{1+85.37 e^{-9.12 \mathrm{DH}} 9}-0.009$ \\
\hline 10 & $L_{10}=\frac{-1.41}{1+0.06 e^{3.75 \mathrm{DHI} 10}}+1.333$ \\
\hline
\end{tabular}

complexity of the wheat production system. It is not only time-consuming, but also very difficult to obtain satisfactory accuracy by calibrating and validating the EPIC model while adjusting parameters manually (Wang et al. 2013; Yin et al. 2014).

We therefore suggest that the calibration and validation of the EPIC model should seek overall optimization, not relying on one or a few of the parameters, for obtaining satisfactory wheat yield simulation results. We thus propose partition parameter optimization according to the law of regional differentiation in wheat-planting areas (Jia 2010; Jia et al. 2012; Wang et al. 2012, 2013; Yin et al. 2014). From a technical perspective, the overall optimization goal was achieved using a detailed, regional wheat-planting calendar and optimized genetic parameters of wheat for the EPIC model, with the support of the SCE- 
UA parameter optimization method. This ensures that the model output obtains high accuracy compared with observed data and provides for the reliability of wheat drought vulnerability curves in general. Because the SCE-UA parameter calibration is performed by a computer, it is temporally efficient. Although the simulated yield changes more gradually than the observed yield, it is clearer in the validation result, whereas the overall trends of simulated and observed yields are quite good.

\subsection{Regional wheat vulnerability curves}

We also produced more highly accurate regional wheat vulnerability curves than can qualitative indicators of vulnerability, which can only produce a relative vulnerability rating (Kim et al. 2013). The proposed curves reveal the quantitative relationship between drought and wheat yield loss rate. Moreover, the 11 regional wheat vulnerability curves make it possible to better understand spatial differences in Chinese wheat drought vulnerability, than do two vulnerability curves for just spring wheat and winter wheat (Wang et al. 2013). Our detailed wheat vulnerability curves also represent a strong scientific basis for evaluating the risk of wheat subjected to drought at a variety of scales with the same high precision. We therefore suggest that wheat drought management should be based on the wheat drought vulnerability of different wheat-planting regions.

Although the wheat drought vulnerability curves were built taking the difference in climatic conditions and time frames into account, wheat variety, which determines the genetic parameters of wheat, was not considered, because of the large number of wheat varieties that change frequently in different regions of China. It is also difficult to measure the effect of changes in wheat variety on wheat production improvement at a regional scale in different periods because of a lack of observed data, although this can easily be done in a laboratory. We assume a steady wheat variety in all wheat-panting regions, so that the spatial differences can be fully compared for wheat drought vulnerability, a comparison that has great significance for the development of regional mitigation strategies to combat wheat drought.

\subsection{Potential improvements for better model performance}

The proposed approach for constructing regionalized vulnerability curves has room for improvement. The model performance is not currently optimal, for one. For example, in regions 4, 6, 7, 8, and 9 (their modified vulnerability curves are shown in Fig. 5), most points converge on high drought hazard intensity, which coincides with the actual situation of high drought intensity in these regions (Fig. 7). However, the problem is not fully addressed because the vulnerability curves for these regions obtain a certain degree of deformation, and the curves of region 6 and 8 do not fit very well ( $R^{2}$ equals 0.34 and 0.25$)$. The DHI used here is such that the duration of water stress is as important as its magnitude. However, when the magnitude of water stress becomes large enough to kill the crop, even when the duration is short, the drought intensity is in fact much larger than we estimated. To fully address this problem, a more comprehensive drought index should be established. In other words, this index should be able to indicate the drought intensity for the point at which the crop will nearly die and should then assign a high corresponding value. Additionally, wheat variety and agricultural management should also be taken into account as EPIC model inputs in future research. Despite this, the proposed regionalized vulnerability curve-building approach can also be a potential reference for building crop drought vulnerability curves in different geographical areas at multiple scales. 

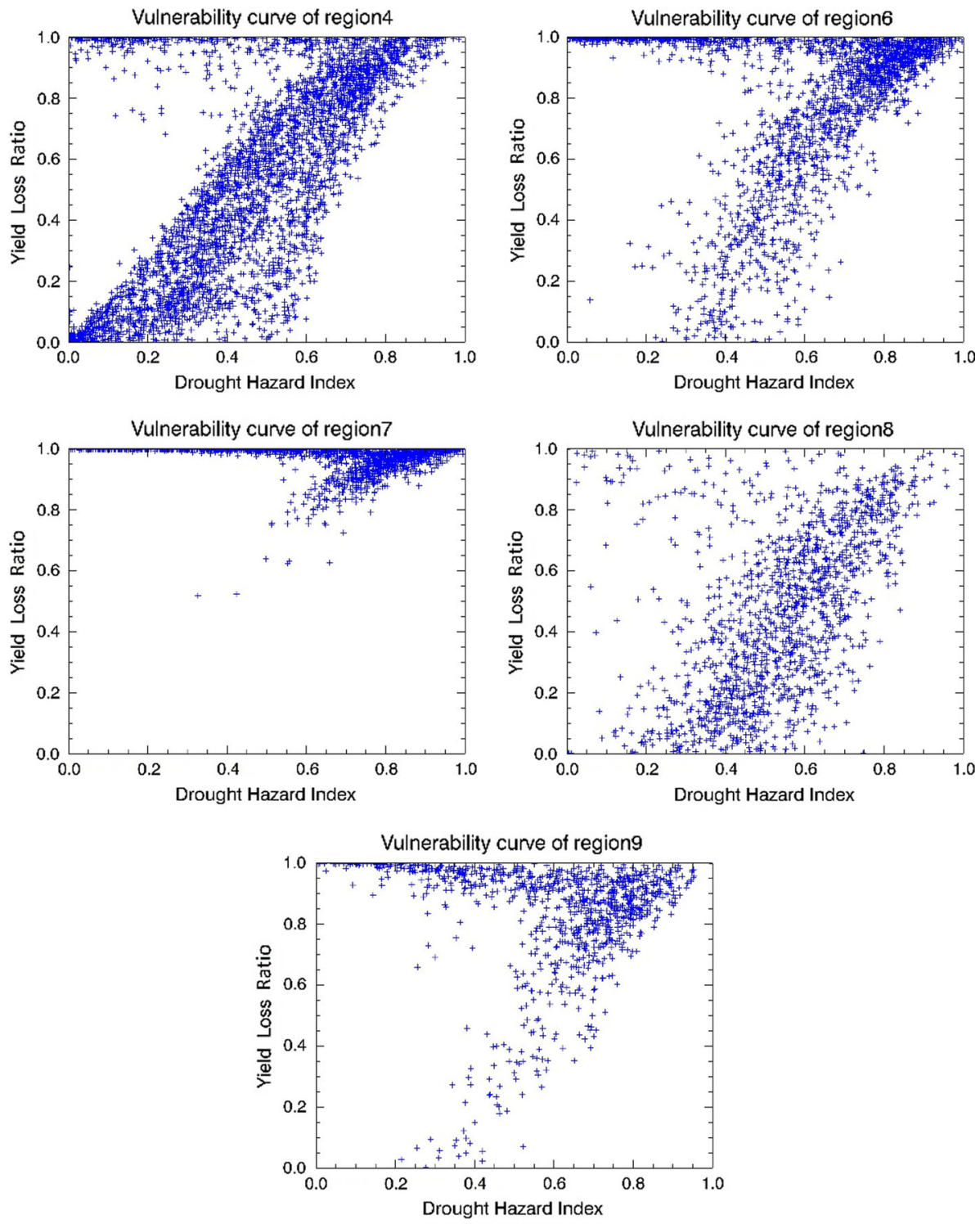

Fig. 7 Regions that have high yield loss rate even the DHI is low

\section{Conclusions}

This paper proposed an EPIC model-based analytical approach to developing regionalized vulnerability curves for wheat subjected to drought. The vulnerability curves are divided according to regions of wheat planting, with support from the SCE-UA method. The best regional wheat sowing and harvesting dates and optimized wheat varieties (i.e., genetic parameters of wheat) were then identified, to differentiate the agricultural systems of the 
wheat-planting regions. With these improvements, we achieve more detailed and precise wheat drought vulnerability estimates for China than have been found previously.

Detailed wheat vulnerability estimates make it possible to better understand spatial differences in the vulnerability of wheat to drought in China. We find that the South China Winter Wheat Region, the Huang-Huai Winter Wheat Region, the North Winter Wheat Region, the Xinjiang Winter Wheat Region, and the North Xinjiang Spring Wheat Region are more vulnerable than other regions. Once a wheat-planting region is identified, the method allows for the selection and use of the appropriate set of vulnerability curves to assess the expected yield loss. Regionalized wheat vulnerability curves provide a strong scientific basis for evaluating the risk of wheat subjected to drought at a variety scales but with the same level of precision. Because it allows for the comparison of wheat drought vulnerability between areas, this research is significant in the development of regional mitigation strategies for combating drought. We therefore suggest that wheat drought management should be based on the wheat drought vulnerability of different wheatplanting regions.

Further improvements could be made to this approach. A more comprehensive drought index should be established, and wheat variety and agricultural management should also be taken into account as EPIC model inputs in future research. However, the proposed regionalized vulnerability curve-building approach provides a potential reference for developing crop drought vulnerability curves for different geographical areas at multiple scales.

Acknowledgments This study was supported by the National Natural Science Foundation of China (No.41171402) and the National Key Basic Research Program of China (No. 2012CB955403). The Natural Science Research Program of Jiangsu (14KJA170001), the Priority Academic Program Development of Jiangsu Higher Education Institutions, Program of International S\&T Cooperation, Ministry of Science and Technology of China (Project No. 2010DFB24140). The support received by A-Xing Zhu through the Vilas Associate Award, the Hammel Faculty Fellow, and the Manasse Chair Professorship from the University of Wisconsin-Madison and through the "One-Thousand Talents" Program of China is also greatly appreciated. The authors would like to thank the anonymous reviewers for their comments to improve the quality of this article.

\section{References}

Angstrom A (1924) Solar and terrestrial radiation. Report to the international commission for solar research on actinometric investigations of solar and atmospheric radiation. Q J R Meteorol Soc 50(210):121-126

Birkmann J (ed) (2006) Measuring vulnerability to promote disaster-resilient societies: conceptual frameworks and definitions. In: Measuring vulnerability to natural hazards: towards disaster resilient societies. United Nations University Press, Tokyo, pp 9-54

Blaikie P, Cannon TD, Davis II, Wisner B (1994) At risk: natural hazards, people's vulnerability and disasters. Routledge, London

Brooks N (2003) Vulnerability, risk and adaptation: a conceptual framework. Tyndall Cent Clim Change Res Work Pap 38:1-16

Cao Y, Yang J, Xiong W et al (2014) Simulation of winter wheat yield influenced by potential drought in China during 1962-2010. Trans Chin Soc Agric Eng 30(7):128-139 in Chinese

Chaney WR (1981) Sources of water. Water Deficits Plant Growth 6:1-47

Colombi M, Borzi B, Crowley H, Onida M, Meroni F, Pinho R (2008) Deriving vulnerability curves using Italian earthquake damage data. Bull Earthq Eng 6(3):485-504. doi:10.1007/s10518-008-9073-6

Cutter SL (1996) Vulnerability to environmental hazards. Prog Hum Geogr 20:529-539

Duan Q, Sorooshian S, Gupta V (1992) Effective and efficient global optimization for conceptual rainfallrunoff models. Water Resour Res 28(4):1015-1031 
Duan Q, Gupta VK, Sorooshian S (1993) Shuffled complex evolution approach for effective and efficient global minimization. J Optim Theory Appl 76(3):501-521

Duan Q, Sorooshian S, Gupta VK (1994) Optimal use of the SCE-UA global optimization method for calibrating watershed models. J Hydrol 158(3):265-284

Dutta D, Herath S, Musiake K (2003) A mathematical model for flood loss estimation. J Hydrol 277(1-2):24-49. doi:10.1016/s0022-1694(03)00084-2

FAO (2011) http://faostat3.fao.org/search/wheat/E/. Download in 11-12-2014

Field CB, Barros V, Stocker TF, Dahe Q (2012) Managing the risks of extreme events and disasters to advance climate change adaptation: special report of the intergovernmental panel on climate change. Cambridge University Press, Cambridge

Gaiser T, de Barros I, Sereke F, Lange F-M (2010) Validation and reliability of the EPIC model to simulate maize production in small-holder farming systems in tropical sub-humid West Africa and semi-arid Brazil. Agric Ecosyst Environ 135(4):318-327. doi:10.1016/j.agee.2009.10.014

Ganji A, Ponnambalam K, Khalili D, Karamouz M (2006) Grain yield reliability analysis with crop water demand uncertainty. Stoch Environ Res Risk Assess 20(4):259-277. doi:10.1007/s00477-005-0020-7

He B, Lü A, Wu J, Zhao L, Liu M (2011) Drought hazard assessment and spatial characteristics analysis in China. J Geogr Sci 21(2):235-249

Hohl R, Schiesser H-H, Aller D (2002) Hailfall: the relationship between radar-derived hail kinetic energy and hail damage to buildings. Atmos Res 63(3):177-207

ISDR (United Nations International Strategy for Disaster Reduction) (2002) Living with risk. A global review of disaster reduction initiatives. ISDR, Geneva

Jia H (2010) Corn drought disaster risk assessment of China. Dissertation, Beijing normal university. in Chinese

Jia H, Wang J, Cao C, Pan D, Shi P (2012) Maize drought disaster risk assessment of China based on EPIC model. Int J Digit Earth 5(6):488-515

Jiang G, Yu F, Zhao Y (2012) An analysis of vulnerability to agricultural drought in China using the expand grey relation analysis method. Procedia Eng 28:670-676. doi:10.1016/j.proeng.2012.01.789

Kim DH, Yoo C, Kim T-W (2011) Application of spatial EOF and multivariate time series model for evaluating agricultural drought vulnerability in Korea. Adv Water Resour 34(3):340-350. doi:10.1016/ j.advwatres.2010.12.010

Kim H, Park J, Yoo J, Kim T-W (2013) Assessment of drought hazard, vulnerability, and risk: a case study for administrative districts in South Korea. J Hydro-environ Res. doi:10.1016/j.jher.2013.07.003

Lee KH, Rosowsky DV (2005) Fragility assessment for roof sheathing failure in high wind regions. Eng Struct 27(6):857-868. doi:10.1016/j.engstruct.2004.12.017

Li J, Yue Y, Pan H, Ye X (2014) Variation rules of meteorological drought in China during 1961-2010 based on SPEI and intensity analysis. J Catastrophol 29(4):176-182 in Chinese

Liu J (2009) A GIS-based tool for modelling large-scale crop-water relations. Environ Model Softw 24(3):411-422. doi:10.1016/j.envsoft.2008.08.004

Liu J, Fritz S, van Wesenbeeck CFA, Fuchs M, You L, Obersteiner M, Yang H (2008) A spatially explicit assessment of current and future hotspots of hunger in Sub-Saharan Africa in the context of global change. Glob Planet Change 64(3-4):222-235. doi:10.1016/j.gloplacha.2008.09.007

McCarthy JJ (2001) Climate change 2001: impacts, adaptation, and vulnerability: contribution of Working group II to the third assessment report of the intergovernmental panel on climate change. Cambridge University Press, Cambridge

Merz B, Kreibich H, Thieken A, Schmidtke R (2004) Estimation uncertainty of direct monetary flood damage to buildings. Nat Hazards Earth Syst Sci 4(1):153-163

National Soil Survey Office (1994) Chinese soil genus records. China Agriculture Press, Beijing in Chinese

Prescott J (1940) Evaporation from a water surface in relation to solar radiation. Trans R Soc S Aust 64:114-118

Rinaldi Michele (2001) Application of EPIC model for irrigation scheduling of sunflower in Southern Italy. Agric Water Manag 49(3):185-196. doi:10.1016/S0378-3774(00)00148-7

Sharpley AN, Williams JR (1990) EPIC_-erosion/productivity impact calculator. I. Model documentation. US Department of Agriculture Technical Bulletin No. 1768, 235 pp

Shi X, Yu D, Warner E, Pan X, Petersen G, Gong Z, Weindorf DC (2004) Soil database of 1:1,000,000 digital soil survey and reference system of the Chinese genetic soil classification system. Soil Surv Horiz 45:129-136

Sullivan CA (2011) Quantifying water vulnerability: a multi-dimensional approach. Stoch Environ Res Risk Assess 25(4):627-640. doi:10.1007/s00477-010-0426-8

Tobler WR (1970) A computer movie simulating urban growth in the Detroit region. Econ Geogr 46:234-240 
Turner BL 2nd, Kasperson RE, Matson PA, McCarthy JJ, Corell RW, Christensen L, Eckley N, Kasperson JX, Luers A, Martello ML, Polsky C, Pulsipher A, Schiller A (2003a) A framework for vulnerability analysis in sustainability science. Proc Natl Acad Sci USA 100(14):8074-8079. doi:10.1073/pnas. 1231335100

Turner BL 2nd, Matson PA, McCarthy JJ, Corell RW, Christensen L, Eckley N, Hovelsrud-Broda GK, Kasperson JX, Kasperson RE, Luers A, Martello ML, Mathiesen S, Naylor R, Polsky C, Pulsipher A, Schiller A, Selin H, Tyler N (2003b) Illustrating the coupled human-environment system for vulnerability analysis: three case studies. Proc Natl Acad Sci USA 100(14):8080-8085. doi:10.1073/pnas. 1231334100

Wang C (2007) Research progress of major agricultural meteorological disasters. Chinese Meteorological Press, Beijing

Wang X, He X, Williams J, Izaurralde R, Atwood J (2005) Sensitivity and uncertainty analyses of crop yields and soil organic carbon simulated with EPIC. Trans Am Soc Agric Eng 48(3):1041

Wang Z, He F, Li J, Liao Y (2012) Assessment on drought risk of typical wheat in China based on EPIC model. Agric Res Arid Areas 30(5):210-215 in Chinese

Wang Z, He F, Fang W, Liao Y (2013) Assessment of physical vulnerability to agricultural drought in China. Nat Hazards 67(2):645-657. doi:10.1007/s11069-013-0594-1

Wilhelmi OV, Wilhite DA (2002) Assessing vulnerability to agricultural drought: a Nebraska case study. Nat Hazards 25(1):37-58

Williams JR (1995) The EPIC model. In: Singh VP (ed) Computer models of watershed hydrology. Water Resources Publications, Highlands Ranch, CO, pp 909-1000

Williams JR, Jones C, Dyke PT (1984) The EPIC model and its application. In: Proceedings of the ICRISAT-IBSNAT-SYSS symposium on minimum data sets for agrotechnology transfer, pp 111-121

Williams JR, Jones CA, Kiniry JR, Spanel DA (1989) The EPIC crop growth model. Trans ASAE 32(2):497-511

Wisner B (ed) (2004) At risk: natural hazards, people's vulnerability and disasters. Psychology Press, London

Wu H, Wilhite DA (2004) An operational agricultural drought risk assessment model for Nebraska, USA. Nat Hazards 33(1):1-21

Wu J, Yu F, Chen Z, Chen J (2009) Global sensitivity analysis of growth simulation parameters of winter wheat based on EPIC model. Trans Chin Soc Agric Eng 25(7):136-142

Wu J, He B, Lü A, Zhou L, Liu M, Zhao L (2011) Quantitative assessment and spatial characteristics analysis of agricultural drought vulnerability in China. Nat Hazards 56(3):785-801. doi:10.1007/ s11069-010-9591-9

Wu D, Yan D, Yang G, Wang X., Xiao W, Zhang H (2013) Assessment on agricultural drought vulnerability in the Yellow River basin based on a fuzzy clustering iterative model. Nat Hazards 67(2):919-936

Xu Y, Zhang X, Ran Q, Tian Y (2013) Impact of climate change on hydrology of upper reaches of Qiantang River Basin, East China. J Hydrol 483:51-60

Yin Y, Zhang X, Lin D, Yu H, Shi P (2014) GEPIC-VR model: a GIS-based tool for regional crop drought risk assessment. Agric Water Manag 144:107-119. doi:10.1016/j.agwat.2014.05.017

Yoo C, Kim S, Kim TW (2006) Assessment of drought vulnerability based on the soil moisture PDF. Stoch Environ Res Risk Assess 21(2):131-141. doi:10.1007/s00477-006-0050-9

Zhang Q, Xiao M, Singh VP, Chen X (2013a) Copula-based risk evaluation of hydrological droughts in the East River basin, China. Stoch Environ Res Risk Assess 27(6):1397-1406. doi:10.1007/s00477-0120675-9

Zhang Z, Wang P, Chen Y et al (2013b) Spatio-temporal changes of agrometrorological disasters for wheat production across China since 1990. Acta Geogr Sin 68(11):1453-1460 in Chinese

Zhao G (2010a) Study on Chinese wheat planting regionalization (I). J Triticeae Crops 30(5):886-895 in Chinese

Zhao G (2010b) Study on Chinese wheat planting regionalization (II). J Triticeae Crops 30(6):1140-1147 in Chinese 